\title{
Iatrogenic parasitic leiomyoma after robotic surgery, managed during cesarean section: Case Report
}

\author{
Nisreen M Anfinan* \\ Department of Obstetrics and Gynecology, Gynecology Oncology Unit, Faculty of Medicine, King Abdulaziz University, Jeddah, Saudi Arabia
}

\begin{abstract}
Parasitic myomas is a rare variant of pedunculated subserosal myoma that got separated partially or completely from the uterus and started receiving blood supply from the omentum or mesenteric vessels. It could be spontaneous or iatrogenic parasitic myomas with previous laparoscopic surgical procedure. We reported here a 35-year-old woman, primigravida at 39 weeks pregnancy, with previous history of uterine myomectomy removed by robotic surgery four years ago. A sonographic diagnosis of leiomyomata was made in the anterior wall of the uterus and another one in the posterior aspect of the lower uterine segment; the course of her pregnancy was unremarkable.
\end{abstract}

The decision was to have elective cesarean section. After delivery of the fetus and closure of the lower cesarean section incision, five sub-serous fibroids and three large multiple parasitic fibroids attached to the omentum were successfully excised using a vessel-sealing hemostatic device. Pathological diagnosis was leiomyoma.

\begin{abstract}
Abbreviation: FIGO: Federation of International Gynecology and Obstetric.

\section{Introduction}

The incidence of uterine leiomyoma during pregnancy is estimated at $2 \%$ [1]. It is usually asymptomatic but may be occasionally complicated by red degeneration which causes acute abdominal pain; other complications include spontaneous abortion, preterm labor, premature rupture of membrane; mal-presentation increases the risk of cesarean section and postpartum hemorrhage $[1,2]$. Because of the increased vascularization of the uterus during pregnancy, surgical removal is generally avoided during pregnancy or cesarean section [3]. However, several reports have shown that myomectomy during cesarean delivery in carefully selected cases can be safe [3-6]. We present a case of multiple sub-serous and parasitic fibroids diagnosed during pregnancy which was successfully managed by myomectomy during cesarean section.
\end{abstract}

\section{Case presentation}

\section{History, examination and management}

A 35-year old booked in our center and was admitted on 4th February 2015 as primigravida at 39 weeks pregnancy duration. She had history of myomectomy removed by robotic surgery in 2011; the fibroid was removed using morcellator without complication. The pregnancy was uncomplicated on examination, with abdomen gravid uterus and approximately $4 \mathrm{~kg}$ size fetus. Abdominal sonography showed an intra-uterine viable singleton fetus of 39 weeks +5 days gestation. The sonography also revealed multiple fibroid structures in the anterior uterine wall measuring $5 \times 3.3 \mathrm{~cm}$ and also in the posterior aspect of the lower uterine segment $2.8 \times 3.2 \mathrm{~cm}$.

Blood tests showed a hematocrit of $35.6 \%$, and normal electrolytes, urea and creatinine levels with A Rhesus positive blood group. Cesarean section was performed under general anesthesia with endotracheal intubation. Operative findings included normal liver, spleen, kidneys, diaphragm, ovaries and fallopian tubes. The uterus was soft and the size was adequate for term gestation. About five sub-serous fibroids and multiple hard lobulated nodules (Figure 1) with thick feeding vessels attached to the omentum; large parasitic fibroids were attached to the omentum, with the largest one measuring $13 \times 7 \times 8 \mathrm{~cm}$. Cesarean section was done and the patient was delivered of a boy weighing 4125 grams with Apgar scores of 8 at one and 10 at five minutes, respectively. Myomectomies of submucous and parasitic fibroid were successfully performed using vessel-sealing device for hemostasis, with estimated blood loss of $850 \mathrm{ml}$. Postoperative period was uneventful and the patient was discharged on day three in good condition. The fibroids weighed about $1.1 \mathrm{~kg}$ and were sent for histopathology (Figure 2). Pathological diagnosis was leiomyoma.

\section{Discussion}

Uterine leiomyomas are the most common uterine neoplasm [7]. They occur in approximately $25 \%$ of reproductive-aged women and are reported on pathological examination in approximately $80 \%$ of hysterectomy specimens $[7,8]$. They are classified according to their location within the myometrium. According to the International Federation of Gynecology and Obstetrics (FIGO), there are eight different types of leiomyoma [9]. Parasitic leiomyoma is a rare variant of leiomyoma, which was first described by Kelly and Cullen in 1909 [10]; it is classically defined as a pedunculated subserosal fibroid that is detached from the uterus, and sustains its growth neovascularization

${ }^{\star}$ Correspondence to: Nisreen M. Anfinan, Gynecology Oncology Unit, Faculty of Medicine, King Abdulaziz University, P.O. Box 80215, Jeddah 21589, Saudi Arabia; Tel: +966 56056 1166; E-mail: dr_nisreen2001@yahoo.com

Key words: fibroid, parasitic, cesarean section

Received: November 12, 2018; Accepted: November 19, 2018; Published: November 26, 2018 


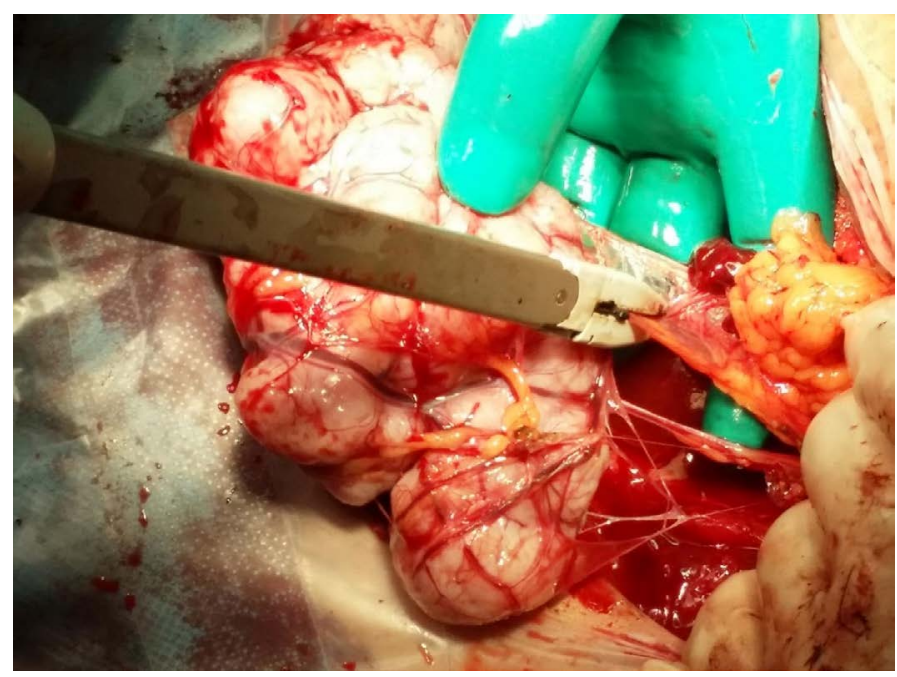

Figure 1. Multiple parasitic myoma swaddled in omentum. these were removed by vessels sealing device after cesarean section

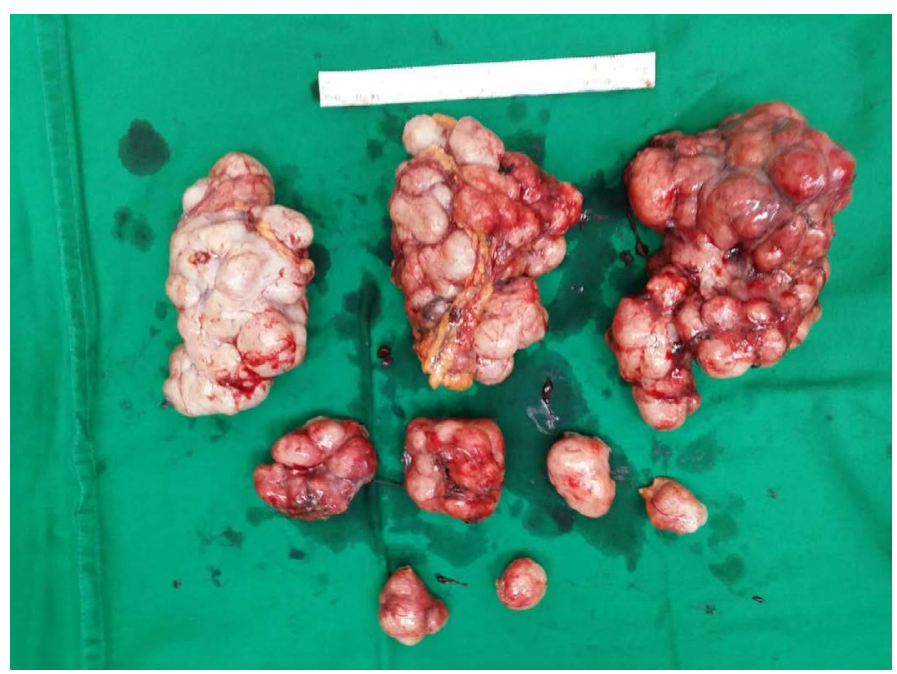

Figure 2. Parasitic myomata after removal

from adjacent tissues, with the blood being supplied from the surface of the omentum or mesenteric vessels. In recent years, with the introduction of minimal invasive surgery for the removal of the uterine leiomyoma and use of morcellation, a new type of parasitic leiomyoma has emerged called iatrogenic parasitic leiomyoma $[7,10,11,12]$. The incidence of parasitic myomectomy after laparoscopic myomectomy is $1.2 \%[7,13]$. Other authors have reported an incidence of $0.12 \%$ after laparoscopic surgery with morcellation [14].

After morcellation, at times pieces of the leiomyoma might be retained in the abdominal cavity where they can then implant and take blood supply from neighboring structures [7]. Parasitic leiomyoma has a similar response to gonadotropin-releasing hormone suppressive treatment $[7,15]$. The most common location of parasitic leiomyomas is the entry point of laparoscopy surgery, they are most often found at the level of the pelvis, and also at the greater omentum peritoneum and bowel $[7,16]$, where there is an area of good blood supply. Our patient had her implant in the greater omentum.

The majority of the cases of parasitic leiomyoma were successfully resected by laparoscopy without complication [17]. Laparotomy approach was indicated for complicated or huge fibroid if malignancy is suspected or with a cesarean section where there is the removal of fibroid after delivery of the fetus. To our knowledge, this is the first case report of removing iatrogenic parasitic fibroid after robotic surgery during cesarean section.

Our experience, in this case, showed that the use of vessels sealing device is important in order to minimize blood loss.

\section{Conclusion}

The number of cases of iatrogenic parasitic fibroid has increased due to the widespread use of power morcellation during laparoscopic surgery. We reported the first case of the successful removal of the iatrogenic parasitic fibroid, after robotic surgery, during cesarean section.

\section{References}

1. Lolis DE, Kalantaridou SN, Makrydimas G, Sotiriadis A, Navrozoglou I, et al "Successful myomectomy during pregnancy". Hum Reprod 18:1699-1702. [Crossref]

2. Brown D, Fletcher HM, Myrie MO, Reid M (1999) Caesarean myomectomy--a safe procedure. A retrospective case controlled study. JObstet Gynaecol 19: 139-141. [Crossref]

3. Ehigiegba AE, Evbuomwan CE (1998) "Inevitable cesarean myomectomy". Trop $J$ Obstet Gynaecol p15:62.

4. Ghaemmaghami F, Karimi-Zarchi M, Gharebaghian M, Kermani T (2017) "Successful Myomectomy during Cesarean Section: Case Report \& Literature Review". Int $J$ Biomed Sci 13: 119-121. [Crossref]

5. Dam Hye Kwon, Ji Eun Song, Kyung Ran Yoon, and Keun Young Lee (2014) “The safety of cesarean myomectomy in women with large myomas". Obstet Gynecol Sci 57: 367-372. [Crossref]

6. H. Li, J. Du, L. Jin, Z. Shi, and M. Liu (2009) "Myomectomy during cesarean section". Obstet Gynecol Survey 64: 363-64.

7. Lete I, González J, Ugarte L, Barbadillo N, Lapuente O, et al. (2016) Parasitic leiomyomas: a systematic review. Eur J Obstet Gynecol Reprod Biol 203: 250-259. [Crossref]

8. Mark Payson, Phyllis Leppert, James Segars, "Epidemiology of Myoma", Obstetric \& Gynaecology Clinical North Am. Author manuscript; available in PMC 2014 Sep 3.

9. Munro MG, Critchley HO, Fraser IS (2011) "FIGO Menstrual Disorders Working Group. The FIGO classification of causes of abnormal uterine bleeding in the reproductive years" Fertil Steril 95:2204-2208. [Crossref]

10. Kelly HA, Cullen TS “Myomata of the uterus”. Philadelphia: WBSaunders 1909.

11. Sinha R, Hegde A, Mahajan C, Dubey N, Sundaram M (2008) "Laparoscopic myomectomy: do size, number, and location of the myomas form limiting factors for laparoscopic myomectomy?," J Minim Invasive Gynecol 15:292-300. [Crossref]

12. Pascual-Pedreño A1, Perez-Medina T, Brouard Urkiaga I, Fernández-Parra J, Sobreviela-Laserrada M (2013) "Practice of endoscopic gynecologic surgery: a survey of Spanish Gynecologists," Eur J Obstet Gynecol Reprod Biol 169: 64-68. [Crossref]

13. Cucinella G, Granese R, Calagna G, Somigliana E, Perino A (2011) "Parasitic myoma after laparoscopic surgery: an emerging complication in the use of morcel- lator? Description of four cases" Fertil Steril 96: e90-96. [Crossref]

14. Leren V, Langebrekke A, Qvigstad E (2012) "Parasitic leiomyomas after laparoscopic surgery with morcellation" Acta Obstet Gynecol Scand 91:1233-1236. [Crossref]

15. Wilkinson N, Rollason TP (2001) Recent advances in the pathology of smooth muscle tumours of the uterus. Histopathology 39: 331-341. [Crossref]

16. Shepperd JA (2012) "Parasitic fibroid presenting as an ovarian mass" J Minim Invasive Gynecol 19: S117.

17. Tyagi J, Jan H, Sarris J, Narvekar N (2014) "Parasitic pedunculated fibroid. Is laparoscopic management the best approach?" J Obstet Gynaecol 34:273-274. [Crossref]

Copyright: (C2018 Anfinan NM. This is an open-access article distributed under the terms of the Creative Commons Attribution License, which permits unrestricted use, distribution, and reproduction in any medium, provided the original author and source are credited. 